\title{
RECURSOS COMPLEMENTARES OU SUBSTITUTOS? UM ESTUDO SOBRE RETENÇÃO DE CAIXA E ALAVANCAGEM FINANCEIRA EM EMPRESAS RESTRITAS E IRRESTRITAS
}

\section{COMPLEMENTARY OR SUBSTITUTE RESOURCES? A STUDY ON CASH HOLDINGS AND FINANCIAL LEVERAGE IN CONSTRAINED AND UNCONSTRAINEDD FIRMS}

\author{
MARÍLIA PARANAÍBA FERREIRA \\ Universidade Federal de Santa Catarina (UFSC) \\ Doutoranda do Programa de Pós-Graduação em Contabilidade (UFSC) \\ Orcid: https://orcid.org/0000-0003-4290-8589 / E-mail: mariliaferreira82@hotmail.com \\ Rua Eng. Agronômico Andrei Cristian Ferreira, s/n - Centro Socioeconômico (CSE), sala 225 \\ Bairro Trindade, Florianópolis - SC, CEP: 88040-970

\begin{abstract}
ERCILIO ZANOLLA
Universidade Federal de Goiás (UFG)

Professor do Curso de Ciências Contábeis e do Programa de Pós-Graduação em Contabilidade (UFG) Doutor em Ciências Contábeis pela Universidade de Brasília - Dinter UnB/UFRN/UFPB Orcid: https://orcid.org/0000-0002-7371-427X / E-mail: zanolla@ufg.br
\end{abstract}

Submissão: 01/02/2021. Revisão: 19/08/2021. Aceite: 23/09/2021. Publicação: 01/02/2022. DOI: http://dx.doi.org/10.22277/rgo.v15i1.6044

\section{RESUMO}

Objetivo: Este estudo objetiva verificar a utilização das reservas de caixa e da alavancagem financeira, de forma complementar ou substituta, pelas empresas classificadas em financeiramente restritas e irrestritas da B3.

Método / abordagem: Os dados do período de 2010 a 2020 foram coletados trimestralmente na base da Economatica e a técnica multivariada de análise fatorial por componentes principais foi adotada para segregar as empresas em restritas e irrestritas conforme o rol de variáveis indicadas pela literatura. Os scores, em ordem crescente, do fator principal foram divididos em quartis, em que o primeiro quartil, extremidade inferior, representou as empresas restritas e o terceiro quartil, extremidade superior, correspondeu ao grupo das irrestritas. No total, 1.482 observações classificadas como sendo de empresas financeiramente restritas e 1.553 observações classificadas como sendo de empresas financeiramente irrestritas foram analisadas por meio de regressões múltiplas com dados em painel.

Principais resultados: As evidências empíricas apontaram que, em média, as empresas restritas retêm mais caixa do que as irrestritas, e que as reservas de caixa e a alavancagem financeira são fontes complementares tanto nas empresas financeiramente restritas quanto nas empresas classificadas como irrestritas.

Contribuições metodológicas / sociais / gerenciais: A contribuição deste estudo é a apresentação de uma perspectiva diferente das Teorias Trade-Off e Pecking Order, no sentido de que a primeira trata os recursos como complementares e a segunda como substitutos.

Originalidade / relevância: Esta pesquisa pode subsidiar investidores, gestores, instituições de crédito e agentes reguladores na compreensão das políticas de caixa e de financiamento.

Palavras-chave: Retenção de caixa. Alavancagem financeira. Restrições financeiras. 
Recursos complementares ou substitutos?

Um estudo sobre retenção de caixa e alavancagem financeira em empresas restritas e irrestritas

\section{ABSTRACT}

Purpose: This study aims to verify the use of cash reserves and financial leverage, in a complementary or substitute manner, by firms classified as financially constrained and unconstrained by B3.

Method / approach: Data for the period 2010 to 2020 were collected quarterly based on Economatica and the multivariate technique of factor analysis by main components was adopted to segregate firms into constrained and unconstrained according to the list of variables indicated in the literature. The scores, in ascending order, of the main factor were divided into quartiles, in which the first quartile, the lower extremity, represented the constrained firms and the third quartile, the upper extremity, corresponded to the unconstrained group. In total, 1,482 observations classified as being from financially constrained firms and 1,553 observations classified as being from financially unconstrained firms were analyzed using multiple regressions with panel data.

Main findings: Empirical evidence shows that, on average, constrained firms retain more cash than unconstrained ones, and that cash reserves and financial leverage are complementary sources in both financially constrained and unrestricted firms.

Methodological / social / managerial contributions: The contribution of this study is the presentation of a different perspective of the Trade-Off and Pecking Order Theories, in the sense that the first treats resources as complementary and the second as substitutes.

Originality / relevance: This research can assist investors, managers, credit institutions and regulatory agents in understanding cash and financing policies.

Keywords: Cash holdings. Financial leverage. Financial constraints.

\section{INTRODUÇÃO}

Compreender as políticas de caixa e financiamento é essencial para a tomada de decisão, pois as empresas demandam recursos para cumprir com suas obrigações e garantir investimentos. Além dos fundos internos, gerados pela própria companhia, a empresa tem a opção de captar recursos no mercado. Nesse sentido, os gestores precisam conhecer o volume de caixa retido pela companhia e analisar a estrutura de capital da firma.

A gestão da liquidez corporativa está diretamente relacionada com as restrições de financiamento (Keynes, 1936). Por isso, empresas restritas financeiramente, ou seja, que possuem acesso limitado ao mercado de crédito (Carvalho \& Kalatzis, 2018), tendem a manter maiores índices de liquidez corporativa, enquanto as irrestritas, neste caso aquelas que possuem acesso não limitado ao mercado de crédito, tendem a manter menores índices de liquidez corporativa (Loncan \& Caldeira, 2014; Manoel et al., 2019).

Denis e Sibilkov (2009) e Franzotti e Valle (2020) relatam que as reservas de caixa são mais relevantes para as empresas que possuem restrições financeiras, já que estão sujeitas a maiores custos de financiamento externo. Ao passo que, como as empresas financeiramente irrestritas conseguem captar recursos no mercado de forma não limitada e a custos menores, normalmente, elas mantêm baixa liquidez e, consequentemente, são mais alavancadas em relação às empresas que apresentam maiores restrições financeiras (Loncan \& Caldeira, 2014).

A Teoria Trade-Off pressupõe que as empresas buscam uma combinação dos recursos próprios e de terceiros, enquanto a Teoria Pecking Order tem como base a hipótese de que as 
empresas seguem uma sequência hierárquica de financiamento (Myers, 1984; Miglo, 2010). Essas duas teorias são discutidas nos trabalhos sobre liquidez corporativa (Loncan \& Caldeira, 2014). Em relação à Trade-Off para os ativos líquidos, as empresas buscam manter um nível ótimo de caixa, definido pelo equilíbrio entre os custos e os benefícios marginais de se manter dinheiro em caixa. No entanto, conforme a Pecking Order, não há um nível alvo de caixa, mas uma ordem hierárquica de utilização dos recursos, em que a empresa utilizaria em um primeiro momento as suas reservas de caixa para, no futuro, utilizar sua capacidade de endividamento.

Diante disso, nota-se que essas teorias são abordadas de maneiras distintas. Enquanto a Trade-Off busca uma combinação ótima, complementar dos recursos internos e externos, a Pecking Order considera esses recursos como substitutos, como mutuamente alternativos, dado que as empresas optam por uma sequência hierárquica das fontes de financiamento: primeiro os recursos internos e depois os externos.

Nesse contexto, partindo do pressuposto de que as reservas de caixa e o capital de terceiros podem apresentar um comportamento complementar ou substituto, o presente estudo busca responder: De que forma, complementar ou substituta, as empresas da B3 classificadas em financeiramente restritas e irrestritas utilizam as reservas de caixa e a alavancagem financeira? Logo, o objetivo é verificar a utilização das reservas de caixa e da alavancagem financeira, de forma complementar ou substituta, pelas empresas classificadas em financeiramente restritas e irrestritas da B3.

Diferentes razões motivam esta pesquisa, como o crescimento dos estudos sobre liquidez corporativa nos últimos anos (Hsu \& Liu, 2018; Karpuz et al., 2020). Além do aumento substancial do caixa em relação ao ativo total (Bates et al., 2018; Aslam et al., 2019), o percentual médio de retenção de caixa apresenta variações significativas entre os países. Nas indústrias americanas a proporção média entre caixa e ativo total passa de $10,5 \%$ para $23,2 \%$ no período entre 1980 e 2006 (Bates et al., 2009), e varia de 2,3\% (Nova Zelândia) a 16,6\% (Hong Kong) entre 1989 e 2009 (Chen et al., 2015).

Posto isto, uma segunda razão é a necessidade de verificar tal relação no contexto brasileiro. O Brasil é um país em desenvolvimento e, portanto, tende a apresentar um comportamento diferente em comparação com os países desenvolvidos (Ermel \& Medeiros, 2020). Também é preciso considerar as divergências econômicas, sociais e regulatórias existentes entre os países e, então, mesmo que a literatura internacional encontre relação positiva ou negativa entre caixa e dívida, os resultados das pesquisas realizadas com dados de outros países não podem, simplesmente, ser generalizados. No Brasil, o custo do capital é alto, o crédito é mais restrito e o volume de negociações diárias é menor (Loncan \& Caldeira, 2014). Além disso, as empresas brasileiras de capital aberto são caracterizadas por alta concentração de ações e baixa proteção legal aos acionistas minoritários (La Porta et al., 2000; Ermel \& Do Monte, 2018).

Outra razão é que o caixa é uma variável relevante da estrutura financeira da empresa, sobretudo em empresas restritas, já que a captação de recursos no mercado pode ser bastante onerosa devido à existência das fricções financeiras como custos de transação, assimetria informacional, impostos e taxa de juros (Manoel et al., 2019), e o custo da ausência de caixa pode prejudicar a solvência das empresas. Al-Najjar e Clark (2017) afirmam que as empresas retêm caixa para evitar financiamento externo caro ou liquidação forçada de ativos, e Huang e Mazouz (2018) relatam que o excesso de caixa diminui o custo de capital próprio e o risco de iliquidez de mercado, e permite a continuidade das operações, dado que este excesso possibilita o financiamento de novas oportunidades. 
Recursos complementares ou substitutos?

Um estudo sobre retenção de caixa e alavancagem financeira em empresas restritas e irrestritas

Destaca-se ainda o fato de que, ao considerar que existe o risco de os gestores praticarem ações que desagregam valor à empresa, oriundo dos problemas de agência entre acionistas-principais e gestores-agentes, normalmente, as empresas com baixa alavancagem estão sujeitas a um menor monitoramento, o que permite ao gestor maior arbitrariedade na tomada de decisão (Ferreira \& Vilela, 2004). Sendo assim, percebe-se a relevância da variável alavancagem financeira para a análise das estratégias de financiamento.

Em relação ao mercado, nota-se que se a empresa não consegue cumprir com suas obrigações e, consequentemente, garantir a continuidade das suas atividades, haverá uma perda do capital investido. Nesse sentido, verificar o comportamento entre a retenção de caixa e a dívida onerosa é uma forma de avaliar a situação econômico-financeira da empresa para, então, detectar possíveis problemas de insolvência.

A literatura tem evidenciado que as restrições financeiras são relacionadas ao custo de financiamento externo (Opler et al., 1999; Denis \& Sibilkov, 2010), ao risco (Palazzo, 2012) e ao motivo de precaução (Bates et al., 2018). Esta pesquisa segue este desenvolvimento, trazendo três contribuições. Primeiro, aborda-se uma perspectiva diferente das Teorias TradeOff e Pecking Order, no sentido de que a primeira trata as reservas de caixa e a alavancagem financeira como fontes complementares e a segunda como fontes substitutas. Segundo, o tratamento metodológico utiliza a técnica multivariada de análise fatorial por componentes principais para classificar as empresas em financeiramente restritas e irrestritas. E, por fim, as empresas estudadas possuem características diversas aos estudos já realizados, uma vez que o custo de oportunidade da liquidez no Brasil é alto devido às altas taxas de juros praticadas (Loncan \& Caldeira, 2014).

\section{FUNDAMENTAÇÃO TEÓRICA E HIPÓTESES DE PESQUISA}

\subsection{ESTRUTURA DE CAPITAL E ENDIVIDAMENTO}

As empresas demandam recursos financeiros para liquidar seus compromissos e realizar investimentos. Esses recursos podem ser obtidos por meio da retenção de lucros, de novos aportes de capital, da captação de crédito com terceiros e da emissão de ações e títulos de dívida.

O trabalho de Modigliani e Miller (1958) revela que, em uma economia perfeita de mercado, o valor da empresa independe de como os recursos são obtidos. Entretanto, posteriormente, Modigliani e Miller (1963) reconhecem que haviam se equivocado e admitem que a alavancagem aumenta o valor da empresa, já que as despesas com juros podem ser deduzidas da base de cálculo do imposto de renda a ser pago pela companhia.

Segundo Myers (1984), a estrutura de capital pode ser interpretada conforme as teorias Trade-Off e Pecking Order. A Trade-Off afirma que o valor da empresa será maximizado por meio da combinação ótima entre o custo e o benefício da dívida. Os custos resultantes da dívida, maiores para os países em desenvolvimento (Chui et al., 2016), seriam os custos de agenciamento da dívida e os custos de falência decorrentes da possibilidade de a empresa enfrentar dificuldades financeiras oriundas da alta alavancagem (Salehi et al., 2017). Já o benefício da dívida seria a vantagem fiscal obtida pela redução das despesas com juros na base de cálculo do imposto de renda a ser pago pela entidade.

Assim, à luz do Trade-Off, o objetivo da firma será se endividar até atingir o ponto de igualdade entre os ganhos fiscais da dívida e os custos esperados de falência. A partir desse ponto, o aumento do endividamento resultará em redução do valor da firma, pois o custo 
marginal esperado da falência irá prevalecer sobre o benefício fiscal marginal da dívida (Myers, 1984).

A outra teoria apresentada por Myers (1984) é chamada de Pecking Order. Essa teoria defende que as empresas optam por uma ordem hierárquica das fontes de financiamento, ou seja, as companhias estabelecem uma sequência prioritária para se financiarem, preferindo os recursos internos aos externos por serem de fácil obtenção e exigirem menor volume de informações (Carvalho \& Kalatzis, 2018). Segundo Myers (1984), as empresas utilizariam primeiro os recursos internos, em seguida os créditos obtidos com terceiros e, por último, a emissão de novas ações preferenciais e ordinárias, respectivamente. Por existir essa ordem de utilização dos recursos, Myers (1984) afirma que empresas mais rentáveis tendem a se endividar menos e Ataünal e Aybars (2017) relatam que empresas lucrativas operam com baixos níveis de endividamento.

Além das teorias Trade-Off e Pecking Order apresentadas, a Teoria da Agência (TA) também pode explicar a estrutura de capital das empresas (Ferreira \& Vilela, 2004). Na tentativa de alinhar os interesses entre gestores (agentes) e acionistas (principais), Jensen (1986) relata que o endividamento pode limitar as atividades irregulares dos agentes, pois quando a empresa aumenta o seu volume de dívida, os gestores são motivados a aumentar também o fluxo de caixa livre da empresa em resposta ao aumento dos custos de falência oriundos da alavancagem. Deste modo, o endividamento reduz a arbitrariedade que os gestores possuem quando a empresa apresenta recursos disponíveis e obriga os gestores a serem mais eficientes.

\subsection{LIQUIDEZ CORPORATIVA}

A gestão da liquidez corporativa é um tema frequente de investigação (Florackis \& Sainani, 2018; Phan et al., 2019). Conforme Keynes (1936), as empresas retêm caixa para liquidar os seus custos operacionais - motivo de transação; garantir as oportunidades de investimentos que podem surgir - motivo de especulação; e se precaverem de incertezas futuras - motivo de precaução.

Conforme Koshio (2005), definir o nível de caixa da empresa é uma tarefa complexa, pois grande parte das transações realizadas em uma companhia tem relação com os fluxos de caixa. Adicionalmente, este autor relata que a análise do nível de caixa envolve, de forma simultânea, vários outros aspectos, como questões de governança corporativa, problemas de agência, estratégia de investimento, políticas de financiamento e de dividendos.

Se os mercados financeiros fossem perfeitos e funcionassem como o esperado, o nível de liquidez das empresas seria irrelevante (Opler et al., 1999; Almeida et al., 2014). Entretanto, devido à presença de friç̧ões financeiras no mercado como impostos, custos de transação, taxa de juros e assimetria informacional, que impedem algumas empresas de financiarem totalmente suas atividades e projetos de investimentos, o volume de liquidez corporativa é relevante para a tomada de decisão.

Ferreira e Vilela (2004), Koshio (2005) e Loncan e Caldeira (2014) relatam que as teorias Trade-Off e Pecking Order também são discutidas nos estudos sobre liquidez corporativa. Ao considerar a Trade-Off no contexto da liquidez, as empresas buscam manter um nível ótimo de caixa, representado pela igualdade entre os custos e os benefícios marginais de se manter caixa nas empresas, e, então, quanto maior o custo e menor o benefício, menor será o nível de caixa da firma.

Em relação aos custos, tem-se o custo de oportunidade de não investir na atividade produtiva da empresa (Loncan \& Caldeira, 2014). Neste caso, a empresa perde o rendimento 
Recursos complementares ou substitutos?

Um estudo sobre retenção de caixa e alavancagem financeira em empresas restritas e irrestritas

se optar por reter o dinheiro ao invés de investir, ou paga juros se precisar captar recursos externos. Já em relação aos benefícios, esses autores pontuam que as reservas de caixa proporcionam maior independência da empresa aos financiamentos externos e menor gasto com custos de transação.

Opler et al. (1999) afirmam que a falta de caixa resulta em maiores custos de transação porque qualquer alternativa que a empresa escolher para aumentar sua liquidez, seja renegociar os empréstimos existentes, reduzir os investimentos e dividendos e vender outros ativos para transformá-los em caixa, terá a incidência desses custos. Al-Najjar e Clark (2017) explicam que as empresas retêm caixa para cumprir com obrigações relacionadas às operações cotidianas, como meio de prevenir potenciais imprevistos e para não negar oportunidades rentáveis de investimento, com o objetivo de evitar financiamento externo caro ou liquidação forçada de ativos. Adicionalmente, Huang e Mazouz (2018) destacam que o excesso de caixa pode chamar a atenção de novos traders por diminuir o custo de capital próprio e o risco de iliquidez de mercado e, também, por possibilitar o financiamento de oportunidades rentáveis.

Por outro lado, se a Pecking Order for considerada, a empresa irá seguir uma ordem hierárquica de utilização dos recursos. Primeiramente, os recursos internos serão consumidos e, em seguida e nesta ordem, os recursos de terceiros e próprios. Para Ferreira e Vilela (2004), o caixa representa um "amortecedor" entre as necessidades de investimentos e os lucros retidos e, por isso quando os lucros não são suficientes, a firma irá utilizar suas reservas de caixa antes de se endividar.

Além das teorias Trade-Off e Pecking Order, a TA é considerada por Ferreira e Vilela (2004) como outro modelo teórico que ajuda a explicar as decisões de liquidez da firma. Conforme esses autores, os gestores possuem incentivos para acumular caixa, pois um aumento das reservas de caixa proporciona um aumento da quantidade de ativos sob o controle da gestão, que por sua vez aumenta o poder discricionário dos gerentes sobre as decisões de investimento. Assim, se as empresas mantêm níveis elevados de caixa, os gestores podem utilizá-los em projetos de VPL negativo somente para atender seus interesses próprios.

Deste modo, o nível de caixa mantido pelas empresas pode ser explicado, por exemplo, pelas teorias Trade-Off, Pecking Order e da Agência abordadas acima e, ainda, pelo dilema entre liquidez e rentabilidade. A liquidez de uma empresa deve ser suficiente para garantir que os compromissos assumidos sejam pagos. Logo, se a companhia mantém um saldo de caixa menor do que o necessário, ela corre o risco de sofrer sanções resultantes da incapacidade de cumprir com as suas obrigações. Em contrapartida, se ao invés de aplicar os recursos em projetos de investimentos rentáveis a empresa opta por manter um alto volume de caixa, ela pode perder boas oportunidades de ganhos. Posto isso, é preciso que os administradores considerem a relação entre liquidez, risco e retorno.

\subsection{RESTRIÇÕES FINANCEIRAS}

Carvalho e Kalatzis (2018) relatam que uma empresa é classificada como financeiramente restrita se o custo ou a falta de disponibilidade dos fundos externos impedir que a empresa realize os investimentos que faria caso possuísse fundos internos disponíveis. Fazzari et al. (1988) explicam que se a diferença entre os custos de financiamento interno e externo for significativa, as empresas financeiramente restritas irão reter uma parte expressiva dos lucros e, portanto, as decisões de investimento serão dependentes dos recursos internos disponíveis. 
Nesse sentido, Franzotti e Valle (2020) afirmam que as decisões de liquidez estão diretamente relacionadas às restrições de crédito, por isso as firmas que se deparam com dificuldades de acesso ao mercado de crédito tendem a manter ativos mais líquidos como tentativa de garantir que as suas obrigações sejam liquidadas nas datas aprazadas. Ao passo que se a empresa não enfrenta restrições de crédito, não há necessidade de reter caixa para investir em futuros projetos, visto que a companhia consegue captar recursos no mercado se houver necessidade (Iquiapaza \& Amaral, 2008).

Conforme visto anteriormente, a Pecking Order defende que a escolha das fontes de financiamento segue uma ordem hierárquica. Essa ordem, formalmente reconhecida por Myers (1984) e Myers e Majluf (1984), seria: primeiro, os recursos gerados internamente; em seguida, as novas dívidas; depois, a emissão de novas ações. Se existir uma ordem hierárquica de uso das fontes de financiamento, a estrutura de capital da empresa irá depender da disponibilidade dessas fontes. Fazzari et al. (1988) ressaltam que pode haver uma hierarquia na utilização dos recursos financeiros, já que o custo dos recursos internos tende a ser menor que o custo dos recursos externos (Bernanke et al., 1994). Diante disso, considerando que as empresas irrestritas não possuem acesso limitado ao crédito (Carvalho \& Kalatzis, 2018; Franzotti \& Valle, 2020), elabora-se a primeira hipótese dessa pesquisa:

$H_{1}$ : As reservas de caixa e a alavancagem financeira são fontes de financiamento substitutas nas empresas financeiramente irrestritas.

Assim como apontado por Almeida e Campello (2010), espera-se que o efeito negativo dos fundos internos sobre a demanda por financiamento externo esteja concentrado nas firmas irrestritas, ou seja, nas firmas menos propensas a enfrentar altos custos de financiamento externo.

Ainda segundo Almeida e Campello (2010), as empresas que apresentam restrições financeiras perdem oportunidades de investimentos rentáveis por estarem sujeitas a custos elevados de financiamento externo. Como consequência, esses autores evidenciam que os fundos internos e externos são mais complementares para as empresas financeiramente restritas, devido à interdependência das decisões de investimento e financiamento. Deste modo, elabora-se a segunda hipótese:

$\mathrm{H}_{2}$ : As reservas de caixa e a alavancagem financeira são fontes de financiamento complementares nas empresas financeiramente restritas.

Fazzari et al. (1988) afirmam que o investimento pode depender de fatores financeiros, como disponibilidade de financiamento interno, acesso ao financiamento de capital ou novas dívidas, ou ainda do funcionamento do mercado de crédito. Por isso, na visão desses a utores, o capital externo não substitui perfeitamente os fundos internos, particularmente no curto prazo. Sendo assim, acredita-se que para as empresas financeiramente restritas essas fontes de recursos são complementares e, portanto, espera-se uma relação positiva entre a retenção de caixa e a alavancagem financeira.

Em linhas gerais, os estudos nacionais e internacionais sobre esta temática investigaram principalmente, os efeitos das restrições financeiras nos investimentos e nas políticas de caixa e financiamento das empresas. Fazzari et al. (1988) avaliaram a sensibilidade do investimento ao fluxo de caixa e encontraram que essa sensibilidade aumenta de acordo com o grau de restrição que a companhia enfrenta. Entretanto, Kaplan e Zingales (1997) questionaram os achados de Fazzari et al. (1988), alegando que das 49 empresas consideradas por Fazzari et al. 
Recursos complementares ou substitutos?

Um estudo sobre retenção de caixa e alavancagem financeira em empresas restritas e irrestritas

(1988) como sendo as mais restritas, menos de 15\% não enfrentavam, obrigatoriamente, dificuldades em captar recursos no mercado.

Enquanto o trabalho de Aldrighi e Bisinha (2010) corrobora as evidências de Kaplan e Zingales (1997), o estudo de Arslan et al. (2006) corrobora os achados de Fazzari et al. (1988). Para Aldrighi e Bisinha (2010), os investimentos das empresas de grande porte, consideradas como irrestritas, apresentaram maior sensibilidade aos fluxos de caixa e, para Arslan et al. (2006), as empresas financeiramente restritas apresentaram maior sensibilidade do investimento ao fluxo de caixa do que as empresas sem restrições.

Faulkender e Wang (2006) constataram que o valor marginal do caixa é menor para as empresas que apresentam melhor acesso ao mercado de crédito. Adicionalmente, Denis e Sibilkov (2010) relataram que as disponibilidades de caixa são valiosas, principalmente para as empresas que possuem restrições financeiras, tendo em vista que essas empresas poderão utilizar as reservas de caixa disponíveis em novos projetos de VPL positivo quando surgirem.

Já os estudos de Almeida et al. (2004) e Byrro e Bressan (2016) indicaram que a sensibilidade do caixa ao fluxo de caixa é positiva para as empresas com restrições financeiras. Além disso, Opler et al. (1999), Frésard e Salva (2010) e Manoel et al. (2019) constataram que empresas financeiramente restritas tendem a manter maiores reservas de caixa.

\section{METODOLOGIA}

Esta pesquisa é classificada como descritiva de abordagem quantitativa. A amostra é composta por empresas ativas de capital aberto que negociaram ações na B3 entre 2010 e 2020, com exceção das empresas classificadas pela B3 nos setores "Financeiro", "Utilidade Pública" e "Outros" e das observações que apresentaram patrimônio líquido negativo.

As empresas classificadas nos setores "Financeiro" e "Utilidade Pública" são excluídas por serem regulamentadas de forma específica e possuírem classificação e definição distintas quanto ao critério, nomenclatura e composição das contas, e as empresas do setor "Outros" são desconsideradas devido ao fato de este grupo conter majoritariamente empresas de participações.

Já as observações com patrimônio líquido negativo são retiradas por serem consideradas impróprias para estudos sobre estrutura de capital devido às perdas acumuladas (Loncan \& Caldeira, 2014). Os parâmetros considerados na coleta dos dados e construção das variáveis são o uso de demonstrações consolidadas, da classe $\mathrm{ON}$ e de dados trimestrais ajustados pelo IPCA conforme a Economatica. As variáveis do estudo são apresentadas na Tabela 1.

Tabela 1

Variáveis do estudo

\begin{tabular}{|c|c|c|c|}
\hline \multicolumn{4}{|c|}{ Variável Dependente } \\
\hline Variável & Descrição & Sinal Esperado & Fonte \\
\hline $\begin{array}{l}\text { Retenção de Caixa } \\
\qquad(\mathrm{rc})\end{array}$ & $\begin{array}{l}\text { Mensurada pelo caixa e } \\
\text { equivalentes de caixa divididos } \\
\text { pelo ativo total. }\end{array}$ & & $\begin{array}{l}\text { Dittmar et al. (2003); Harford et al. } \\
\text { (2008) }\end{array}$ \\
\hline \multicolumn{4}{|c|}{ Variável Independente de Interesse } \\
\hline Variável & Descrição & Sinal Esperado & Fonte \\
\hline $\begin{array}{l}\text { Alavancagem } \\
\text { Financeira (alav) }\end{array}$ & $\begin{array}{l}\text { Mensurada pela razão entre a } \\
\text { soma da dívida* de curto e longo } \\
\text { prazo e o ativo total. }\end{array}$ & $\begin{array}{l}\text { Empresa: } \\
\text { restrita (+); } \\
\text { irrestrita (-) }\end{array}$ & $\begin{array}{l}\text { Opler et al. (1999); Bates et al. } \\
\text { (2009); Franzotti e Valle (2020) }\end{array}$ \\
\hline
\end{tabular}


Marília Paranaíba Ferreira e Ercilio Zanolla

\begin{tabular}{|c|c|c|c|}
\hline \multicolumn{4}{|c|}{ Variáveis de Controle } \\
\hline Variável & Descrição & Sinal Esperado & Fonte \\
\hline $\begin{array}{l}\text { Oportunidades de } \\
\text { Investimento } \\
\text { (qtobin) }\end{array}$ & $\begin{array}{l}\text { O q de Tobin é utilizado como } \\
\text { proxy para oportunidades de } \\
\text { investimento e é mensurado pela } \\
\text { soma do valor de mercado e das } \\
\text { dívidas divididos pelo ativo total. }\end{array}$ & $(+)$ & $\begin{array}{l}\text { Opler et al. (1999); D'Mello et al. } \\
\text { (2008); Portal et al. (2012) }\end{array}$ \\
\hline $\begin{array}{l}\text { Tamanho da } \\
\text { Empresa (tam) }\end{array}$ & $\begin{array}{l}\text { Representado pelo logaritmo } \\
\text { natural }(I n) \text { do ativo total. }\end{array}$ & $(-)$ & $\begin{array}{l}\text { Opler et al. (1999); Portal et al. } \\
\text { (2012); Franzotti e Valle (2020) }\end{array}$ \\
\hline $\begin{array}{l}\text { Capital de Giro } \\
\text { Líquido (cgl) }\end{array}$ & $\begin{array}{l}\text { Representado pelo capital de giro } \\
\text { menos o caixa e equivalentes de } \\
\text { caixa dividido pelo ativo total. }\end{array}$ & $(-)$ & $\begin{array}{l}\text { Opler et al. (1999); Harford et al. } \\
\text { (2008); Bates et al. (2009) }\end{array}$ \\
\hline $\begin{array}{c}\text { Nível de } \\
\text { Governança } \\
\text { Corporativa (gov) }\end{array}$ & $\begin{array}{l}\text { Mensurado por uma variável } \\
\text { dummy, em que um (1) a } \\
\text { empresa pertence ao Nível } 2 \text { ou } \\
\text { Novo Mercado; e zero (0) caso } \\
\text { contrário. }\end{array}$ & $(+)$ & $\begin{array}{l}\text { Harford et al. (2008); Al-Najjar } \\
\text { (2015) }\end{array}$ \\
\hline Fluxo de Caixa (fcx) & $\begin{array}{l}\text { É o caixa gerado pelas atividades } \\
\text { operacionais. }\end{array}$ & $(+)$ & $\begin{array}{l}\text { Opler et al. (1999); Ferreira e Vilela } \\
\text { (2004); Harford et al. (2008); Bates } \\
\text { et al. (2009) }\end{array}$ \\
\hline $\begin{array}{l}\text { Pagamento de } \\
\text { Dividendos (div) }\end{array}$ & $\begin{array}{l}\text { Mensurado por uma variável } \\
\text { dummy, em que um (1) a } \\
\text { empresa efetuou pagamento de } \\
\text { dividendos e/ou juros sobre o } \\
\text { capital próprio; e zero (0) caso } \\
\text { contrário. }\end{array}$ & $(-)$ & $\begin{array}{l}\text { Opler et al. (1999); Dittmar et al. } \\
\text { (2003); Harford et al. (2008); Bates } \\
\text { et al. (2009); Bao et al. (2012) }\end{array}$ \\
\hline $\begin{array}{l}\text { Despesa de Capital } \\
\text { (despcap) }\end{array}$ & $\begin{array}{l}\text { Mensurada pela razão entre as } \\
\text { despesas financeiras e o ativo } \\
\text { total. }\end{array}$ & $(-)$ & $\begin{array}{l}\text { Harford et al. (2008); Bates et al. } \\
\text { (2009); Chen et al. (2015) }\end{array}$ \\
\hline
\end{tabular}

Nota: *a dívida corresponde ao somatório dos empréstimos e financiamentos e debêntures.

\subsection{CLASSIFICAÇÃO DAS EMPRESAS EM FINANCEIRAMENTE RESTRITAS E IRRESTRITAS}

Diferentes variáveis, como (1) índice de pagamento, (2) tamanho da empresa, (3) fluxo de caixa, (4) pagamento de dividendos, (5) lucratividade, (6) q de Tobin, (7) alavancagem, (8) índice da dívida, (9) ativo total e (10) despesa financeira sobre o ebitda, podem ser utilizadas para segregar as empresas em financeiramente restritas e irrestritas (Brown \& Petersen, 2011; Byrro \& Bressan, 2016) e, segundo Denis e Sibilkov (2009), não há um consenso a respeito de qual critério representa melhor as restrições financeiras. Nesse sentido, aplica-se neste estudo a técnica multivariada de análise fatorial por componentes principais, que resulta em um conjunto de variáveis inter-relacionadas conhecido como fator principal e considerado como representante de dimensões nos dados (Hair et al., 2009).

Antes de gerar o fator, é preciso definir a matriz de correlação para cada par de variáveis e verificar a adequação global da análise fatorial por meio da estatística KaiserMeyer-Olkin (KMO) e do teste de esfericidade de Bartlett. Como a matriz de correlação pode variar entre -1 e +1 e os valores mais próximos de 0 (zero) indicam que a relação entre duas variáveis é praticamente inexistente (Fávero \& Belfiore, 2017), das dez variáveis mencionadas no parágrafo anterior, cinco são utilizadas por apresentarem correlações lineares significativas e maiores que 0,50: índice de pagamento, que representa a razão entre a soma do pagamento 
Recursos complementares ou substitutos?

Um estudo sobre retenção de caixa e alavancagem financeira em empresas restritas e irrestritas

de dividendos e de juros sobre o patrimônio líquido e a receita; tamanho da empresa, representado pelo logaritmo natural da receita; pagamento de dividendos, que corresponde a soma dos valores pagos em dividendos e dos juros sobre o capital próprio; índice da dívida, que é a dívida dividida pelo somatório da dívida e do patrimônio líquido, em que a dívida corresponde ao somatório dos empréstimos e financiamentos e debêntures de curto e longo prazo; e o ativo total, que corresponde ao valor contábil do ativo total. Sobre a adequação global da análise fatorial, a estatística KMO $(K M O=0,602)$ e o teste de esfericidade de Bartlett $\left(X^{2}\right.$ Bartlett $=3279,824>X^{2}$ Crítico da Distribuição Qui-Quadrado $\left.=18,307\right)$ indicam que fatores podem ser extraídos a partir das variáveis originais e, como o autovalor do fator principal (F1) é 1,776 e o percentual de variância compartilhada do F1 com as variáveis originais é aproximadamente 0,60 , utiliza-se o F1 como combinação linear das cinco variáveis originais.

Em seguida, os scores deste F1, após serem organizados em ordem crescente, são segregados em quartis, medida que divide os valores de uma série em quatro partes iguais. Como o 10 quartil, extremidade inferior, contém os menores scores de F1, corresponde as empresas financeiramente restritas e como o 3 quartil, extremidade superior, contém os maiores scores, corresponde ao grupo das irrestritas. O 20 quartil é desconsiderado por representar a mediana, $50 \%$ dos menores valores da série e $50 \%$ dos maiores. Este processo resulta em 1.482 observações classificadas como sendo de empresas financeiramente restritas e 1.553 observações classificadas como sendo de empresas financeiramente irrestritas.

\subsection{MODELO EMPÍRICO E ABORDAGEM ESTATÍSTICA}

Para testar as hipóteses deste estudo, o seguinte modelo empírico é estimado:

$$
\begin{gathered}
r c_{i, t}=\beta_{0}+\beta_{1} \operatorname{alav}_{i, t}+\beta_{2} \text { qtobin }_{i, t}+\beta_{3} \operatorname{tam}_{i, t}+\beta_{4} \operatorname{cgl}_{i, t}+\beta_{5} \text { gov }_{i, t}+ \\
\beta_{6} f c x_{i, t}+\beta_{7} \operatorname{div}_{i, t}+\beta_{8} \operatorname{despcap}_{i, t}+\varepsilon_{i, t}
\end{gathered}
$$

O mesmo modelo empírico é utilizado duas vezes, uma vez com as observações das empresas restritas e outra vez com as irrestritas, e a técnica de winsorização ao nível de $5 \%$ é aplicada para todas as variáveis, exceto as dummies, com o intuito de suavizar à média as observações discrepantes (Chen et al., 2016). Os dados são estruturados em forma de painel não balanceado e os testes $F$ de Chow, LM de Breusch-Pagan e Hausman são realizados para definir o modelo de dados em painel mais adequado. Para verificar a normalidade e homocedasticidade dos resíduos, os testes Shapiro-Francia e de Breush-Pagan são aplicados. Além da Matriz de Correlação de Pearson, calcula-se o VIF para examinar se há multicolinearidade entre as variáveis explicativas.

\section{DESCRIÇÃO E ANÁLISE DOS RESULTADOS}

\subsection{ESTATÍSTICAS DESCRITIVAS}

Primeiramente, somente as observações das empresas classificadas como sem restrições são consideradas. As estatísticas descritivas das variáveis, com exceção das dummies, antes e após a técnica de winsorização são apresentadas na Tabela 2. 
Marília Paranaíba Ferreira e Ercilio Zanolla

Tabela 2

Estatísticas descritivas antes e após a winsorização das observações irrestritas

\begin{tabular}{l|c|c|c|c|c|c|c|c|c}
\hline \multirow{2}{*}{ Var. } & & \multicolumn{2}{|c|}{ Média } & \multicolumn{2}{c|}{ Desvio-padrão } & \multicolumn{2}{c|}{ Mínimo } & \multicolumn{2}{c}{ Máximo } \\
\cline { 3 - 10 } & Obs. & Antes & Após & Antes & Após & Antes & Após & Antes & Após \\
\hline rc & 1617 & 0,077 & 0,075 & 0,079 & 0,073 & 0 & 0 & 0,630 & 0,248 \\
alav & 1617 & 0,337 & 0,331 & 0,236 & 0,221 & 0 & 0 & 1,441 & 0,757 \\
qtobin & 1617 & 1,183 & 1,084 & 1,046 & 0,728 & 0 & 0,190 & 7,080 & 2,854 \\
tam & 1617 & 14,605 & 14,605 & 0,300 & 0,300 & 14,080 & 14,080 & 15,140 & 15,140 \\
cgl & 1617 & 0,127 & 0,124 & 0,187 & 0,163 & $-0,731$ & $-0,170$ & 0,774 & 0,432 \\
fcx & 1617 & 26967,9 & 35794,3 & 339749,2 & 83003,9 & $-1,32 e+07$ & $-201051,5$ & 784968,6 & 784968,6 \\
despcap & 1553 & 0,015 & 0,014 & 0,029 & 0,010 & $-0,121$ & 0,001 & 0,929 & 0,039 \\
\hline
\end{tabular}

Nota: Var. representa as variáveis e Obs. corresponde ao número de observações. Os dados estão em milhares.

Após a winsorização, destacam-se as mudanças da maior parte das estatísticas descritivas do fluxo de caixa, do desvio-padrão do $q$ de Tobin, dos valores mínimos do $q$ de Tobin, capital de giro líquido e despesa de capital e dos valores máximos da retenção de caixa, alavancagem, $q$ de Tobin e despesa de capital. Sobre a retenção de caixa, nota-se que o desviopadrão é menor que a média e quanto ao $q$ de Tobin, observa-se que a média antes e após a suavização das observações é maior que 1, o que indica que, em média, o valor da empresa é maior que o custo do investimento.

Em seguida, para identificar se as reservas de caixa e a alavancagem financeira são fontes de financiamento complementares nas empresas financeiramente restritas, apenas as observações das empresas restritas são consideradas. As estatísticas descritivas das variáveis, com exceção das dummies, antes e após o procedimento de winsorização são descritas na Tabela 3.

Tabela 3

Estatísticas descritivas antes e após a winsorização das observações restritas

\begin{tabular}{l|c|c|c|c|c|c|c|c|c}
\hline \multirow{2}{*}{ Var. } & & \multicolumn{2}{c|}{ Média } & \multicolumn{2}{c|}{ Desvio-padrão } & \multicolumn{2}{c|}{ Mínimo } & \multicolumn{2}{c}{ Máximo } \\
\cline { 3 - 9 } & Obstes & Após & Antes & Após & Antes & Após & Antes & Após \\
\hline rc & 1618 & 0,092 & 0,091 & 0,069 & 0,065 & 0 & 0 & 0,355 & 0,248 \\
alav & 1618 & 0,419 & 0,405 & 0,227 & 0,192 & 0,009 & 0,009 & 1,439 & 0,757 \\
qtobin & 1618 & 1,200 & 1,146 & 0,856 & 0,662 & 0,067 & 0,190 & 8,057 & 2,854 \\
tam & 1618 & 17,499 & 17,323 & 0,952 & 0,603 & 16,194 & 16,194 & 20,940 & 18,066 \\
cgl & 1618 & 0,053 & 0,057 & 0,140 & 0,131 & $-0,567$ & $-0,170$ & 0,451 & 0,432 \\
fcx & 1618 & 1918220 & 754650,7 & 5211536 & 745043 & $-1,33 e+07$ & $-201051,5$ & $4,98 e+07$ & 1871017 \\
despcap & 1482 & 0,015 & 0,014 & 0,017 & 0,010 & $-0,076$ & 0,001 & 0,214 & 0,039 \\
\hline
\end{tabular}

Nota: Var. representa as variáveis e Obs. corresponde ao número de observações. Os dados estão em milhares.

Em relação à técnica de winsorização, percebe-se que há, de modo geral, alteração significativa nas estatísticas descritivas da variável fluxo de caixa e nos valores mínimos e máximos das variáveis $q$ de Tobin, capital de giro líquido e despesa de capital. Em relação à variabilidade dos dados, constata-se que o fluxo de caixa das empresas irrestritas e restritas varia muito ao longo do período. Além disso, nota-se que nas empresas financeiramente restritas o desvio-padrão da retenção de caixa é menor que a média e que a média do $q$ de Tobin também é maior que 1.

Ao comparar as médias da variável dependente antes e após a winzorização entre as empresas financeiramente restritas e irrestritas (Tabelas 2 e 3), observa-se que, apesar de as empresas irrestritas e restritas apresentarem índices próximos de retenção de caixa e de o valor máximo de retenção de caixa antes da winzorização pertencer a uma empresa irrestrita $(0,63)$, a média de retenção de caixa nas empresas irrestritas $(0,077$ e 0,075$)$ é inferior em relação às empresas restritas $(0,092$ e 0,091). Este resultado corrobora os achados de Brown 
Recursos complementares ou substitutos?

Um estudo sobre retenção de caixa e alavancagem financeira em empresas restritas e irrestritas

e Petersen (2011) e Manoel et al. (2019) de que, em média, as empresas financeiramente restritas retêm mais caixa do que as irrestritas.

Ademais, estudos que investigaram o comportamento do caixa evidenciaram que o nível médio de retenção de caixa se altera entre os países. Enquanto este estudo mostra que o nível médio de retenção de caixa das empresas brasileiras varia entre 7,7\% (irrestrita) e 9,2\% (restrita), o que vai ao encontro do nível de 0,0909 apresentado por Ferreira e Vicente (2020), Schauten et al. (2013) relatam diferenças substanciais entre os níveis médios de retenção de caixa das maiores empresas não financeiras europeias listadas em bolsa, sendo 5,3\% na Áustria, 9,3\% na Espanha, 13,7\% no Reino Unido, 16,4\% na Grécia, 25,4\% na Suíça e 46,1\% na Irlanda.

\subsection{RESULTADOS DAS REGRESSÕES}

Os resultados dos testes $F$ de Chow, LM de Breusch-Pagan e Hausman apontam que o modelo de efeitos fixos é o mais indicado para identificar se as reservas de caixa e a alavancagem financeira são fontes de financiamento substitutas nas empresas financeiramente irrestritas $\left(\mathrm{H}_{1}\right)$ e fontes de financiamento complementares nas empresas financeiramente restritas $\left(\mathrm{H}_{2}\right)$. Contudo, tendo em vista que o modelo de efeitos fixos omite as estimativas dos coeficientes e efeitos marginais das variáveis que são invariantes ao longo do tempo e que o painel é desbalanceado, adota-se o modelo POLS na análise dos dados.

Nos dois modelos empíricos, um para as observações irrestritas e outro para as observações restritas, os resíduos não seguem distribuição normal. Porém, a ausência de normalidade não é de fato um problema, pois os modelos empíricos contêm $1.553\left(\mathrm{H}_{1}\right)$ e 1.482 $\left(\mathrm{H}_{2}\right)$ observações e, segundo Brooks (2014), a violação deste pressuposto é virtualmente irrelevante nos estudos que investigam grandes quantidades de observações e frequente nos modelos econômicos e de finanças. Como, em ambos os casos, os resultados rejeitam a hipótese nula de variância constante, os modelos são estimados com erros-padrão robustos para minimizar os problemas de heterocedasticidade. Ademais, constata-se que não há multicolinearidade entre as variáveis explicativas, visto que todos os VIFs são iguais ou menores que 2,13 e que as correlações significativas são inferiores a 0,60 (Hair Jr. et al., 2009), conforme denota a Tabela 4.

Tabela 4

Matriz de correlação de Pearson

\begin{tabular}{|c|c|c|c|c|c|c|c|c|c|}
\hline & $\mathrm{rc}$ & alav & qtobin & tam & cgl & gov & $f c x$ & div & descap \\
\hline rc & 1,0000 & & & & & & & & \\
\hline alav & $0,1105^{*}$ & 1,0000 & & & & & & & \\
\hline qtobin & $0,1532 *$ & $0,1007^{*}$ & 1,0000 & & & & & & \\
\hline tam & $0,0766^{*}$ & 0,2999* & $0,1997^{*}$ & 1,0000 & & & & & \\
\hline cgl & $-0,2379 *$ & $-0,2253^{*}$ & $0,0783^{*}$ & $-0,1710 *$ & 1,0000 & & & & \\
\hline gov & 0,0999* & $0,2593^{*}$ & $0,3150 *$ & $0,2570 *$ & 0,0187 & 1,0000 & & & \\
\hline$f(x$ & $0,0778 *$ & $0,0583^{*}$ & $0,0927^{*}$ & $0,5942^{*}$ & $-0,2078 *$ & $-0,0150$ & 1,0000 & & \\
\hline div & $0,1182^{*}$ & $-0,0435^{*}$ & $0,2220^{*}$ & $0,2067^{*}$ & $0,0414^{*}$ & $-0,0544 *$ & $0,2413^{*}$ & 1,0000 & \\
\hline descap & 0,0027 & $0,3980 *$ & $-0,0352 *$ & $0,0552 *$ & $-0,2372 *$ & $0,0382 *$ & $0,0273^{*}$ & $-0,1015^{*}$ & 1,0000 \\
\hline
\end{tabular}

Nota: * significância estatística de 0,05.

Os resultados das regressões são demonstrados na Tabela 5. 
Tabela 5

Resultados das regressões

\begin{tabular}{l|c|c}
\hline \multicolumn{2}{c}{ Variável Dependente: Retenção de Caixa } & $\mathbf{H}_{\mathbf{2}}$ (Restritas) \\
\hline Variáveis Independente de Interesse e de Controle & $\mathbf{H}_{\mathbf{1}}$ (Irrestritas) & $0,049^{* * *}$ \\
\hline Alavancagem financeira (alav) & $0,023^{* * *}$ & $(5,12)$ \\
& $(2,62)$ & $0,014^{* * *}$ \\
Q de Tobin (qtobin) & $0,005^{*}$ & $(5,45)$ \\
Tamanho (tam) & $(1,69)$ & $-0,009^{* * *}$ \\
& $-0,019^{* * *}$ & $(-2,64)$ \\
Capital de giro líquido (cgl) & $(-3,50)$ & $-0,170^{* * *}$ \\
& $-0,096^{* * *}$ & $(-14,41)$ \\
Nível de governança (gov) & $(-9,19)$ & $0,017^{* * *}$ \\
& $0,017^{* * *}$ & $(5,20)$ \\
Fluxo de caixa (fcx) & $(3,33)$ & $-4,89 \mathrm{e}-09^{*}$ \\
& $6,21 \mathrm{e}-08^{* * *}$ & $(-1,90)$ \\
Pagamento de dividendos (div) & $(2,65)$ & $0,009^{* * *}$ \\
& $0,023^{* * *}$ & $(2,74)$ \\
Despesa de capital (despcap) & $(5.89)$ & $-0,498^{* * *}$ \\
& $-0,038$ & $(-3,21)$ \\
Constante (_cons) & $(-0.19)$ & $0,212^{* * *}$
\end{tabular}

Nota: $* * * / * / *$ correspondem a uma significância estatística de 0,01/0,05/0,10, respectivamente. Valores da estatística $t$ entre parêntese.

Sobre a hipótese $1\left(\mathrm{H}_{1}\right)$, a relação obtida entre as variáveis retenção de caixa (variável dependente) e alavancagem financeira (independente de interesse) é positiva e estatisticamente significativa ao nível de $1 \%$. Posto isto, rejeita-se $\mathrm{H}_{1}$, uma vez que as evidências indicam que as reservas de caixa e a alavancagem financeira estão associadas como fontes de financiamento complementares nas empresas financeiramente irrestritas, ou seja, que, no contexto sem restrição financeira, empresas mais alavancadas apresentam maiores reservas de caixa.

Nas variáveis de controle $q$ de Tobin, nível de governança, fluxo de caixa e pagamento de dividendos os coeficientes também se mostram positivos e estatisticamente significativos ao nível de $1 \%$ ou $10 \%$. Já o tamanho e capital de giro líquido apresentam significância estatística de $1 \%$ e coeficientes negativos conforme o esperado. Ademais, nota-se pela análise da Tabela 5 que a variável de controle despesa de capital não tem significância estatística e que as variáveis explicativas estatisticamente significativas do modelo com as 1.553 observações trimestrais das empresas irrestritas explicam a retenção de caixa em $10 \%$. Esse percentual é relativamente baixo, talvez porque a maioria das transações realizadas em uma empresa tem relação com o caixa.

Os achados ainda mostram que a hipótese $2\left(\mathrm{H}_{2}\right)$ não é rejeitada, já que a relação encontrada entre as variáveis retenção de caixa e alavancagem financeira é positiva e estatisticamente significativa ao nível de $1 \%$. Logo, pode-se afirmar que, em média, as empresas financeiramente restritas utilizam as reservas de caixa e a alavancagem financeira como recursos complementares. Sobre essa complementaridade dos recursos, de acordo com Fazzari et al. (1988), a realização de determinado investimento depende, por exemplo, do acesso que a empresa tem ao mercado de crédito, por isso o capital externo não substitui perfeitamente os fundos internos nas empresas restritas. 
Recursos complementares ou substitutos?

Um estudo sobre retenção de caixa e alavancagem financeira em empresas restritas e irrestritas

Nas variáveis de controle $q$ de Tobin, nível de governança e pagamento de dividendos os coeficientes também se mostram positivos e estatisticamente significativos ao nível de $1 \%$. Ao passo que os coeficientes do tamanho, capital de giro líquido, fluxo de caixa e despesa de capital são negativos com significância estatística de $1 \%$ ou $10 \%$. Ao comparar os sinais esperados com os obtidos na Tabela 5 para a $\mathrm{H}_{2}$, observa-se que o fluxo de caixa e $\mathrm{o}$ pagamento de dividendos apresentam sinais contrários. Existem possíveis explicações que justificam esses resultados. Sobre o fluxo de caixa, supõe-se que a empresa que possui maior fluxo de caixa consegue aproveitar mais oportunidades de investimento, por isso as disponibilidades tendem a ser menores. Para o pagamento de dividendos, destaca-se que as empresas podem distribuir o excesso de caixa por meio de recompras ao invés dividendos. Além disso, nota-se que as variáveis explicativas estatisticamente significativas do modelo com as 1.482 observações trimestrais das empresas irrestritas explicam a retenção de caixa em aproximadamente $19 \%$.

\section{CONSIDERAÇÕES FINAIS}

Este estudo objetiva verificar a utilização das reservas de caixa e da alavancagem financeira, de forma complementar ou substituta, pelas empresas classificadas em financeiramente restritas e irrestritas da B3. As descobertas empíricas para o período de 2010 a 2020 apontam que, apesar de as empresas irrestritas e restritas apresentarem índices próximos de retenção de caixa e de o valor máximo de retenção de caixa pertencer a uma empresa classificada como irrestrita $(0,63)$, a média de retenção de caixa nas empresas irrestritas é inferior em comparação com as empresas restritas.

Além disso, as evidências indicam que, assim como nas irrestritas, nas empresas brasileiras financeiramente restritas as reservas de caixa e a alavancagem financeira são fontes de financiamento complementares. Este resultado reforça os achados de Almeida e Campello (2010) de que nas empresas restritas os fundos internos e externos são considerados como complementares devido a interdependência das decisões de investimento e financiamento.

Adicionalmente, os trabalhos de Ferreira e Vilela (2004) e Koshio (2005) explicam que as empresas com maior alavancagem optam por manter maiores quantidades de ativos líquidos para reduzir o risco de falência oriundo do peso que os custos dos planos de amortização representam para a gestão do caixa. Isso significa que as empresas buscam uma combinação ótima dos recursos próprios e de terceiros, ou seja, um nível ótimo de caixa, representado pela igualdade entre os custos e os benefícios marginais de se manter caixa, e um ponto ótimo de endividamento, por meio do equilíbrio entre os benefícios fiscais da dívida e os custos esperados de falência, conforme define a Teoria Trade-Off.

Segundo Forti et al. (2011), no início da década de 1990, as empresas que acumulavam caixa eram vistas com desconfiança, já que o alto volume das disponibilidades gera custos pela inatividade dos recursos, reduz a rentabilidade e pode resultar em conflitos de agência. No entanto, devido à presença de friç̧ões financeiras no mercado e ao aumento da restrição de crédito, pesquisas mostram que a retenção de caixa tem suas vantagens, principalmente para as empresas que possuem acesso limitado aos mercados de capitais e, consequentemente, estão sujeitas a maiores custos de financiamento externo.

De acordo com Iturralde et al. (2009), as empresas que retêm participações em caixa evitam custos de transação oriundos da captação de recursos externos e não são forçadas a vender/trocar ativos para liquidar obrigações. Além disso, esses autores relatam que as 
disponibilidades podem ser utilizadas a qualquer momento para financiar atividades e/ou investimentos rentáveis se os recursos externos estão muito onerosos ou indisponíveis. Outra vantagem destacada por Froot et al. (1993) é que empresas com altas reservas de caixa podem restringir a entrada de concorrentes no mercado e desestimular a competição.

A contribuição teórica desta pesquisa é a construção de uma perspectiva diferente das teorias Trade-Off e Pecking Order, no sentido de que a primeira trata os recursos como complementares e a segunda como substitutos, e a empírica é a escolha do método utilizado para segregar as empresas em financeiramente restritas e irrestritas. Percebe-se na literatura sobre restrições financeiras que diferentes variáveis podem ser usadas para segregar as empresas em financeiramente restritas e irrestritas sem um modelo padrão definido. Como limitação, os resultados não podem ser generalizados porque a amostra é não probabilística. Para futuras pesquisas, sugere-se analisar o perfil das empresas restritas e irrestritas, identificar o comportamento da retenção de caixa por setor e verificar a relação do caixa das empresas restritas e irrestritas com o valor de mercado.

\section{REFERÊNCIAS}

Aldrighi, D. M., \& Bisinha, R. (2010). Restrição financeira em empresas com ações negociadas na Bovespa. Revista Brasileira de Economia, 64(1), 25-47.

Almeida, H., \& Campello, M. (2010). Financing frictions and the substitution between internal and external funds. Journal of Financial and Quantitative Analysis, 45(3), 589622.

Almeida, H., Campello, M., Cunha, I., \& Weisbach, M. S. (2014). Corporate liquidity management: A conceptual framework and survey. Annual Review of Financial Economics, 6(1), 135-162. https://doi.org/10.1146/annurev-financial-110613-034502.

Almeida, H., Campello, M., \& Weisbach, M. S. (2004). The cash flow sensitivity of cash. The Journal of Finance, 59(4), 1777-1804. https://doi.org/10.1111/j.15406261.2004.00679.x.

Al-Najjar, B. (2015). The effect of governance mechanisms on small and medium-sized enterprise cash holdings: Evidence from the United Kingdom. Journal of Small Business Management, 53(2), 303-320. https://doi.org/10.1111/jsbm.12062.

Al-Najjar, B., \& Clark, E. (2017). Corporate governance and cash holdings in MENA: Evidence from internal and external governance practices. Research in International Business and Finance, 39, 1-12. https://doi.org/10.1016/j.ribaf.2016.07.030.

Arslan, O., Florackis, C., \& Ozkan, A. (2006). The role of cash holdings in reducing investment-cash flow sensitivity: Evidence from a financial crisis period in an emerging market. Emerging Markets Review, 7(4), 320-338. https://doi.org/10.1016/j.ememar.2006.09.003.

Aslam, E., Kalim, R., \& Fizza, S. (2019). Do cash holding and corporate governance structure matter for the performance of firms? Evidence from KMI 30-and KSE 100-Indexed 
Recursos complementares ou substitutos?

Um estudo sobre retenção de caixa e alavancagem financeira em empresas restritas e irrestritas

Firms in Pakistan. Global Business Review, 20(2), 313-330.

https://doi.org/10.1177/0972150918825202.

Ataünal, L., \& Aybars, A. (2017). Testing target-adjustment and pecking order models of capital structure and estimating speed of adjustment: evidence from Borsa Istanbul (BIST). International Journal of Corporate Finance and Accounting (IJCFA), 4(1), 1-15. https://doi.org/10.4018/IJCFA.2017010101.

Bao, D., Chan, K. C., \& Zhang, W. (2012). Asymmetric cash flow sensitivity of cash holdings. Journal of Corporate Finance, 18(4), 690-700. https://doi.org/10.1016/j.jcorpfin.2012.05.003.

Bates, T. W., Kahle, K. M., \& Stulz, R. M. (2009). Why do U.S. firms hold so much more cash than they used to? The Journal of Finance, 64(5), 1985-2021. https://doi.org/10.1111/j.1540-6261.2009.01492.x.

Bates, T. W., Chang, C. H., \& Chi, J. D. (2018). Why has the value of cash increased over time? Journal of Financial and Quantitative Analysis (JFQA), 53(2), 749-787. http://dx.doi.org/10.2139/ssrn.1975491.

Bernanke, B.; Gertler, M.; \& Gilchrist, S. (1994). The financial accelerator and the flight to quality. The Review of Economics and Statistics, 78(1), 1-15.

Brooks, C. (2014). Introductory econometrics for finance (2a ed.). Cambridge University Press.

Brown, J. R., \& Petersen, B. C. (2011). Cash holdings and R\&D smoothing. Journal of Corporate Finance, 17(3), 694-709. https://doi.org/10.1016/j.jcorpfin.2010.01.003.

Byrro, L. M. N., \& Bressan, A. A. (2016). A sensibilidade do caixa ao fluxo de caixa nas companhias abertas brasileiras: uma análise do período pré e pós-crise de 2008. Revista de Finanças Aplicadas, 7(2), 1-32.

Carvalho, F. L., \& Kalatzis, A. E. G. (2018). Qualidade dos Lucros, Decisões de Investimentos e Restrição Financeira. Revista Brasileira de Gestão de Negócios, 20(4), 573-598. 10.7819/rbgn.v0i0.3067.

Chakraborty, A., Baum, C. F., \& Liu, B. (2017). Corporate financial policy and the value of cash under uncertainty. International Journal of Managerial Finance, 13(2), 149-164. https://doi.org/10.1108/IJMF-12-2015-0210.

Chen, J. L., Jia, Z. T., \& Sun, P. W. (2016). Real option component of cash holdings, business cycle, and stock returns. International Review of Financial Analysis, 45, 97-106. https://doi.org/10.1016/j.irfa.2016.03.008. 
Chen, Y., Dou, P. Y., Rhee, S. G., Truong, C., \& Veeraraghavan, M. (2015). National culture and corporate cash holdings around the world. Journal of Banking \& Finance, 50(1), 118. https://doi.org/10.1016/j.jbankfin.2014.09.018.

Chui, A. C. W.; Kwok, C. C. Y.; Zhou, G. (2016). National culture and the cost of debt. Journal of Banking \& Finance, 69, 1-19. https://doi.org/10.1016/j.jbankfin.2016.04.001.

D'Mello, R., Krishnaswami, S., \& Larkin, P. J. (2008). Determinants of corporate cash holdings: Evidence from spin-offs. Journal of Banking \& Finance, 32(7), 1209-1220. https://doi.org/10.1016/j.jbankfin.2007.10.005.

Denis, D. J., \& Sibilkov, V. (2009). Financial constraints, investment, and the value of cash holdings. Review of Financial Studies, 23(1), 247-269.

https://doi.org/10.1093/rfs/hhp031.

Dittmar, A., Mahrt-Smith, J., \& Servaes, H. (2003). International corporate governance and corporate cash holdings. The Journal of Financial and Quantitative Analysis, 38(1), 111133. https://doi.org/10.2307/4126766.

Ermel, M. D. A., \& Do Monte, P. A. (2018). Controle acionário, remuneração de executivos e desempenho empresarial: Evidências para o mercado brasileiro. Revista Brasileira de Finanças, 16(3), 455-491. http://dx.doi.org/10.2139/ssrn.2963481.

Ermel, M. D. A., \& Medeiros, V. (2020). Plano de remuneração baseado em ações: uma análise dos determinantes da sua utilização. Revista Contabilidade \& Finanças, 31(82), 84-98. https://doi.org/10.1590/1808-057x201907620.

Faulkender, M., \& Wang, R. (2006). Corporate financial policy and the value of cash. The Journal of Finance, 61(4), 1957-1990. https://doi.org/10.1111/j.15406261.2006.00894.x.

Fávero, L. P., Belfiore, P. (2017). Manual de análise de dados: estatística e modelagem multivariada com Excel, SPSS e Stata. Rio de Janeiro: Elsevier.

Fazzari, S. M., Hubbard, R. G., \& Petersen, B. C. (1988). Financing constraints and corporate investment. Brookings Papers on Economic Activity, 1, 141-195. 10.3386/w2387.

Ferreira, M. A., \& Vilela, A. S. (2004). Why do firms hold cash? Evidence from EMU Countries. European Financial Management, 10(2), 295-319. https://doi.org/10.1111/j.13547798.2004.00251.x.

Ferreira, M. P., \& Vicente, E. F. R. (2020). Efeito da Estrutura do Conselho de Administração na Retenção de Caixa das Companhias Abertas. Contextus - Revista Contemporânea de Economia e Gestão, 18(1), 275-289. https://doi.org/10.19094/contextus.2020.44362. 
Recursos complementares ou substitutos?

Um estudo sobre retenção de caixa e alavancagem financeira em empresas restritas e irrestritas

Florackis, C., \& Sainani, S. (2018). How do chief financial officers influence corporate cash policies? Journal of Corporate Finance, 52, 168-191.

https://doi.org/10.1016/j.jcorpfin.2018.08.001.

Forti, C. A. B., Peixoto, F. M., \& Freitas, K. S. (2011). Retenção de caixa, desempenho operacional e valor: um estudo no mercado de capitais brasileiro. Revista de Contabilidade e Organizações, 5(13), 20-33.

Franzotti, T. D. A., \& Valle, M. R. (2020). Impacto de Crises sobre Investimentos e Financiamentos de Companhias Brasileiras: Abordagem no Contexto de Restrições Financeiras. Brazilian Business Review, 17(2), 233-252. http://dx.doi.org/10.15728/bbr.2020.17.2.6.

Frésard, L., \& Salva, C. (2010). The value of excess cash and corporate governance: Evidence from US cross-listings. Journal of Financial Economics, 98(2), 359-384. https://doi.org/10.1016/j.jfineco.2010.04.004.

Froot, K. A., Scharfstein, D. S., \& Stein, J. C. (1993, Dec). Risk Management: Coordinating Corporate Investment and Financing Policies. The Journal of Finance, 48(5), 1629-1658. https://doi.org/10.1111/j.1540-6261.1993.tb05123.x.

Hair Jr., J. F., Black, W. C., Babin, B. J., Anderson, R. E., \& Tatham, R. L. (2009). Análise multivariada de dados (6a ed.). Porto Alegre: Bookman.

Harford, J., Mansi, S. A., \& Maxwell, W. F. (2008). Corporate governance and firm cash holdings in the US. Journal of Financial Economics, 87(3), 535-555. https://doi.org/10.1016/j.jfineco.2007.04.002.

Hsu, A. W., \& Liu, S. H. (2018). Parent-subsidiary investment layers and the value of corporate cash holdings. Review of Quantitative Finance and Accounting , 51(3), 651681. https://doi.org/10.1007/s11156-017-0684-3.

Huang, W., \& Mazouz, K. (2018). Excess cash, trading continuity, and liquidity risk. Journal of Corporate Finance, 48, 275-291. https://doi.org/10.1016/j.jcorpfin.2017.11.005.

Iquiapaza, R. A., \& Amaral, H. F. (2008). Restrições de financiamento e política de gestão de caixa nas empresas da Bovespa. Revista de Informação Contábil, 2(3), 77-89.

Iturralde, T., Maseda, A., Jose, L. S. (2009). Cash management routines: evidence from Spain. Frontiers in Finance and Economics, 6(1), 93-117.

Jensen, M. C. (1986). Agency costs of free cash flow, corporate finance, and takeovers. The American Economic Review, 76(2), 323-329.

Kaplan, S. N., \& Zingales, L. (1997, Feb). Do Investment-Cash Flow Sensitivities Provide Useful Measures of Financing Constraints? The Quarterly Journal of Economics, 112(1), 169215. https://doi.org/10.1162/003355397555163. 
Karpuz, A., Kim, K., \& Ozkan, N. (2020). Employment protection laws and corporate cash holdings. Journal of Banking \& Finance, 111, 105705. https://doi.org/10.1016/j.jbankfin.2019.105705.

Keynes, J. M. (1936). General theory of employment, interest and money. London: Palgrave Macmillan.

Koshio, S. (2005). Nível de caixa de empresas não financeiras no Brasil: determinantes e relação com o endividamento. [Tese de Doutorado, Fundação Getúlio Vargas]. Repositório da Fundação Getúlio Vargas. http://bibliotecadigital.fgv.br/dspace/bitstream/handle/10438/2565/48724.pdf?seque nce $=2 \&$ is Allowed $=y$.

La Porta, R., Lopez-de-Silanes, F., Shleifer, A., \& Vishny, R. W. (2000). Agency problems and dividend policies around the world. The Journal of Finance, 55(1), 1-33. https://doi.org/10.1111/0022-1082.00199.

Loncan, T. R., \& Caldeira, J. F. (2014). Estrutura de capital, liquidez de caixa e valor da empresa: estudo de empresas brasileiras cotadas em bolsa. Revista Contabilidade \& Finanças, 25 (64), 46-59. https://doi.org/10.1590/S1519-70772014000100005.

Manoel, A. A. S., Moraes, M. B. C., Santos, D. F. L., \& Neves, M. F. (2019). The Effects of Financial Constraints on Cash Management: A Study with Private Firms of the Brazilian Sugarcane Industry. Journal of Accounting, Management and Governance, 22(2), 188204. http://dx.doi.org/10.21714/1984-3925_2019v22n2a3.

Miglo, A. (2010). The pecking order, trade-off, signaling, and market-timing theories of capital structure: A review. Working paper. Social Science Research Network.

Modigliani, F.; \& Miller, M. H. (1963). Corporate income taxes and the cost of capital: a correction. The American Economic Review, 53(3), 433-443.

https://www.jstor.org/stable/1809167.

Modigliani, F.; \& Miller, M. H. (1958). The cost of capital, corporation finance and the theory of investment. The American Economic Review, 48(3), 261-297.

https://www.jstor.org/stable/1809766.

Myers, S. C. (1984). The capital structure puzzle. The Journal of Finance, 39(3), 574-592.

Myers, S. C.; \& Majluf, N. S. (1984). Corporate financing and investment decisions when firms have information that investors do not have. Journal of Financial Economics, 13(2), 187-221. 10.3386/w1396.

Opler, T., Pinkowitz, L., Stulz, R., \& Williamson, R. (1999). The determinants and implications of corporate cash holdings. Journal of Financial Economics, 52(1), 3-46. https://doi.org/10.1016/S0304-405X(99)00003-3. 
Recursos complementares ou substitutos?

Um estudo sobre retenção de caixa e alavancagem financeira em empresas restritas e irrestritas

Palazzo, B. (2012). Cash holdings, risk, and expected returns. Journal of Financial Economics, 104(1), 162-185. https://doi.org/10.1016/j.jfineco.2011.12.009.

Phan, H. V., Nguyen, N. H., Nguyen, H. T., \& Hegde, S. (2019). Policy uncertainty and firm cash holdings. Journal of Business Research, 95, 71-82.

https://doi.org/10.1016/j.jbusres.2018.10.001.

Portal, M. T., Zani, J., \& Silva, C. E. S. (2012). Friç̧ões financeiras e a substituição entre fundos internos e externos em companhias brasileiras de capital aberto. Revista Contabilidade \& Finanças - USP, 23(58), 19-32. https://doi.org/10.1590/S151970772012000100002.

Salehi, M., Lotfi, A., \& Farhangdoust, S. (2017). The effect of financial distress costs on ownership structure and debt policy. Journal of Management Development, 36(10), 1216-1229. https://doi.org/10.1108/JMD-01-2017-0029.

Schauten, M. B. J., Van Dijk, D., \& Van der Waal, J. P. (2013). Corporate governance and the value of excess cash holdings of large European firms. European Financial Management, 19(5), 991- 1016. https://doi.org/10.1111/j.1468-036X.2011.00615.x. 